\title{
Five-year survival outcomes with two different high dose rate brachytherapy schedules used in the treatment of cervical carcinoma
}

\author{
Mohsin Khan, M. A. Bilal Hussain, Shahid Ali Siddiqui, Mohd Akram \\ Department of Radiotherapy \& Clinical Oncology, JN Medical College, AMU, Aligarh, Uttar Pradesh, India \\ Contributions: (I) Conception and design: M Khan, MAB Hussain; (II) Administrative support: SA Siddiqui, M Akram; (III) Provision of study material \\ or patients: M Khan, SA Siddiqui, M Akram; (IV) Collection and assembly of data: M Khan, MAB Hussain; (V) Data analysis and interpretation: M \\ Khan, MAB Hussain; (VI) Manuscript writing: All authors; (VII) Final approval of manuscript: All authors. \\ Correspondence to: Mohsin Khan, MD, Assistant Professor, JNMC. Department of Radiotherapy \& Clinical Oncology, JN Medical College, AMU, \\ Aligarh, Uttar Pradesh, India. Email: mohsinkhan793@gmail.com.
}

\begin{abstract}
Background: There is significant variation among different centres concerning total doses and doses per fraction of high dose rate (HDR) brachytherapy in carcinoma cervix management. The main aim of this study was to compare two different HDR brachytherapy schedules in terms of local disease-free survival (DFS) and overall survival (OS).

Methods: In total, 472 patients with cervical carcinoma were treated with curative intent concurrent chemo-radiotherapy followed by HDR intracavitary brachytherapy comparing two schedules of 6.5 Gray (Gy) per fraction for 4 doses or 8 Gy per fraction for 3 doses prescribed at point A.

Results: A total of 260 patients received 6.5 Gy for 4 fractions ( $a r m$ A), while 212 received 8 Gy for 3 fractions (arm B). The majority of patients had stage $2 \mathrm{~b}$ and $3 \mathrm{~b}$ disease. Treatment was completed within $69 \pm 6$ days in arm A while in arm B it was completed within $61 \pm 6$ days. Five-year OS in stage $1 \mathrm{~b} 2$ was $80 \%$ in arm $\mathrm{A}$ and $85 \%$ in arm B; in stage $2 \mathrm{a}, 90 \%$ and $83 \%$; in stage $2 \mathrm{~b}, 71 \%$ and $76 \%$; in stage $3 \mathrm{a}, 60 \%$ and $50 \%$; and in stage $3 \mathrm{~b}, 56 \%$ and $63 \%$, respectively. In stage $4 \mathrm{a}$, none of the patients survived beyond 40 months.

Conclusions: Our results establish the efficacy and safety of 8 Gy per fraction HDR brachytherapy dose in 3 applications for the treatment of cervical carcinoma. Moreover, we have reported the 5 -year survival outcomes stage and sub-group-wise for cervical carcinoma patients treated at a tertiary care centre.
\end{abstract}

Keywords: Brachytherapy (BCT); carcinoma cervix; high dose rate (HDR); survival; stage of disease

Received: 29 July 2021; Accepted: 17 December 2021; Published: 30 March 2022.

doi: $10.21037 /$ tro-21-19

View this article at: https://dx.doi.org/10.21037/tro-21-19

\section{Introduction}

Brachytherapy (BCT) is an integral part of carcinoma cervix management. Concomitant chemo-radiotherapy followed by BCT represents the standard of care in patients with tumours from stage $1 \mathrm{~b} 2$ to stage $4 \mathrm{a}$. High dose rate (HDR), and low dose rate (LDR) BCT are relatively equivalent based on the results from various retrospective and prospective studies (1-9). Advantages of HDR-BCT include avoidance of exposure to staff, outpatient treatment, consistent and reproducible applicator positioning, and dose optimization with a variable dwell-time stepping source (1). Viswanathan et al. (10) in a survey of the gynecologic cancer intergroup concluded that, with the use of HDR-BCT, there is significant variation among different centres with respect to the total tumour dose, dose per fraction and the proportion of tumour dose delivered with external beam radiotherapy (EBRT), versus that delivered by BCT. There is widespread use of 6 Gray (Gy) for 5 fractions HDR-BCT in cervical carcinoma, especially in the United States, after the publication of various guidelines $(11,12)$. 
Given the potential for short- and long-term injury to normal tissues from large doses per fraction as in HDRBCT, it is imperative on the part of the treating physician that total doses and doses per fraction should be carefully selected. A range of total doses and doses per fraction is being used at our centre, with the two most frequent schedules of 6.5 Gy for 4 fractions or 8 Gy for 3 fractions, at the discretion of the treating physician. With the main aim to compare these two schedules for the treatment of carcinoma cervix and to report the 5-year local diseasefree survival (DFS) and overall survival (OS) stagewise, this present study was conducted. We present the following article in accordance with the STROBE reporting checklist (available at https://tro.amegroups.com/article/ view/10.21037/tro-21-19/rc).

\section{Methods}

Case records of all the patients diagnosed, staged and treated as per the 2009 update of the International Federation of Gynecology and Obstetrics (FIGO) system between January 2010 to June 2016 were reviewed. Out of these all who were treated with curative intent using EBRT concurrent with chemotherapy followed by BCT were retrospectively analyzed. Only those patients who completed their treatment as planned and who were followed up till June 2021 were included. In total, 472 case records were finally available for analysis. Investigations like cystoscopy, proctoscopy, ultrasonography, abdominal and pelvic computed tomography/magnetic resonance imaging etc. were routinely performed. Carcinoma in situ of the cervix was not registered and only cases of invasive cervical cancer were included. The study was conducted in accordance with the Declaration of Helsinki (as revised in 2013). The study was approved by the institutional ethics committee of Faculty of Medicine, JN Medical College, Aligarh Muslim University (No. IECJNMC/395) and individual consent for this retrospective analysis was waived.

\section{Radiotherapy}

\section{External beam}

Curative intent radiation therapy was given with a combination of EBRT and a HDR intra-cavitary BCT (HDR-BCT). EBRT was done with $2 \mathrm{D}$ planning. The fields were directed to the whole pelvis with parallel opposed anteroposterior or 4-field box technique from L4-L5 interspace superiorly to bottom of obturator foramen inferiorly, $1.5-2 \mathrm{~cm}$ from the widest point on pelvic brim laterally and sacral hollow posteriorly to anterior of symphysis pubis anteriorly with cobalt- 60 teletherapy machine using conventional simulator. A total dose of 50 Gy in 25 fractions in 5 weeks with 2 Gy per fraction was utilised.

\section{Intracavitary brachytherapy}

HDR-BCT was started within 7 days after completion of EBRT and was performed with iridium-192 application. We compared two HDR-BCT schedules, i.e., 6.5 Gy for 4 fractions to a total dose of $26.0 \mathrm{~Gy}$ ( $\mathrm{arm} \mathrm{A}$ ) and 8 Gy for 3 fractions to a total dose of 24 Gy ( $\mathrm{arm} \mathrm{B}$ ) prescribed at point A. These two schedules are commonly employed at our institute to treat carcinoma cervix.

\section{Chemotherapy}

Chemotherapy was administered to all patients. Cisplatin at a dose of $40 \mathrm{mg} / \mathrm{m}^{2}$ at weekly intervals was administered during the EBRT phase.

\section{Toxicity analysis}

All patients were evaluated for late normal tissue complications, especially for gastrointestinal (GI) and genitourinary $(\mathrm{GU})$ systems. Complications were graded according to Radiation Therapy Oncology Group (RTOG) Late Morbidity Scoring.

\section{Statistical analysis}

Comparison of the two schedules was done in terms of local DFS, OS and late toxicities. DFS was defined as the time from treatment to recurrence of the tumour (at the local site and excluded the recurrence at the nodal site) or death. OS was defined as the time from treatment to death from any cause. Statistical analyses were performed using Statistical Package for Social Sciences (SPSS) software. Statistical significance of the difference in proportions and means was calculated using the $\chi^{2}$ test or the $t$-test. DFS and OS were calculated using the Kaplan-Meier method. A P value of $<0.05$ was considered significant.

\section{Results}

\section{Patients and treatment}

We retrospectively analyzed 472 patients treated for 
Table 1 Patient, treatment and tumor characteristics

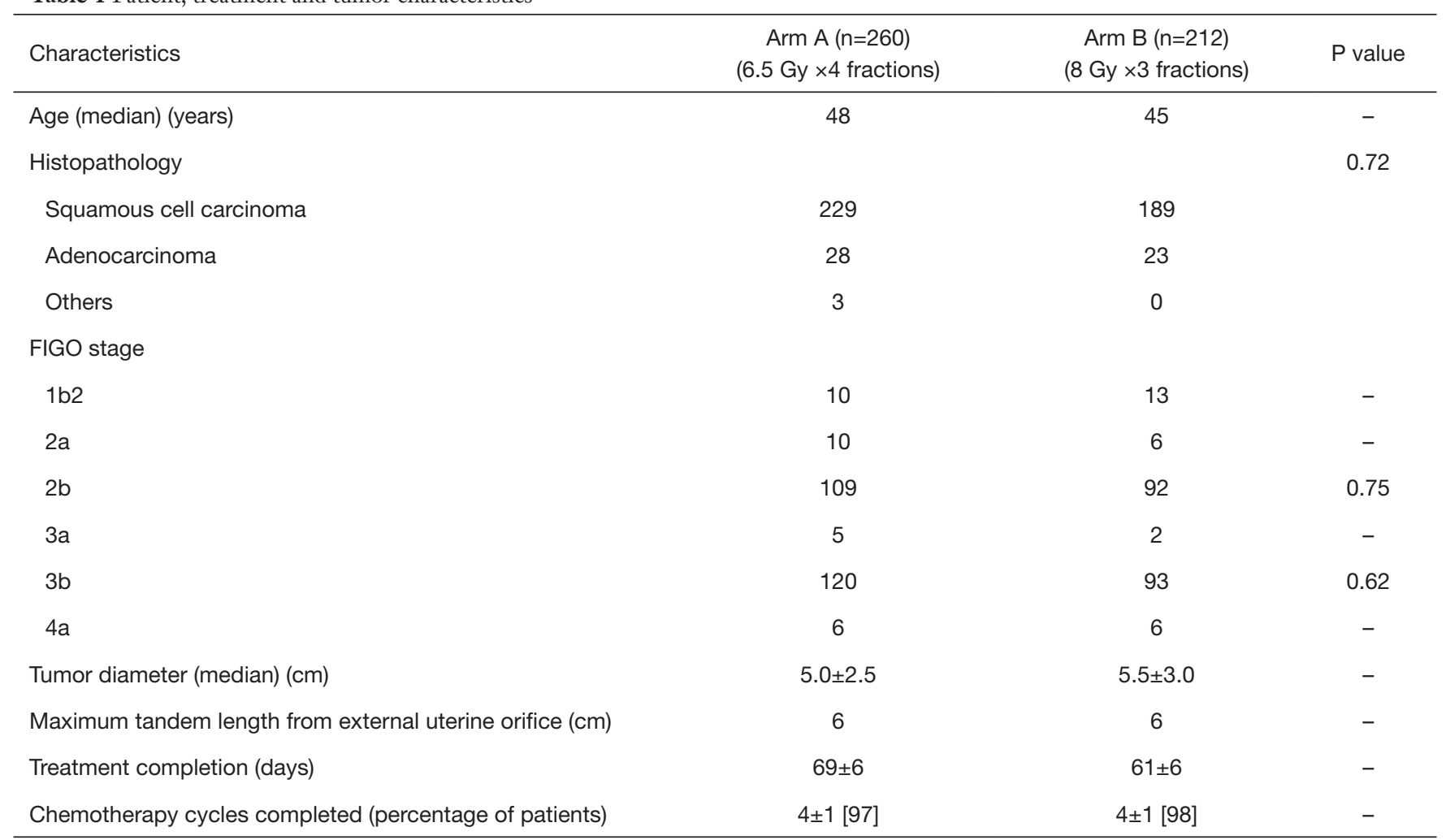

FIGO, International Federation of Gynecology and Obstetrics.

carcinoma cervix from January 2010 to June 2016. The last follow-up was done on June 2021 for the analysis of data. A total of 260 were treated with 6.5 Gy for 4 fractions (arm A), while 212 received 8 Gy for 3 fractions ( $\operatorname{arm~B)}$. The median age was 48 and 45 years respectively in arms $\mathrm{A}$ and $\mathrm{B}$, with squamous cell carcinoma being the main histopathological diagnosis. The majority of patients had stage $2 \mathrm{~b}$ and $3 \mathrm{~b}$ disease $(41.9 \%$ and $46.1 \%$ in arm $\mathrm{A}$ and $43.4 \%$ and $43.8 \%$ in arm B). The mean tumour diameter was $5 \pm 2.5 \mathrm{~cm}$ in arm A and $5.5 \pm 3 \mathrm{~cm}$ in arm B, as assessed by computed tomography. The maximum tandem length was $6 \mathrm{~cm}$ in both arms from the external uterine orifice. Treatment was completed within $69 \pm 6$ days in arm A while in arm B it was completed within $61 \pm 6$ days. The majority of the patients received and completed their chemotherapy cycles as planned (Table 1).

\section{Toxicity analysis}

We mainly reported late GI and GU toxicities suffered as the worst toxicity by the patients. Five percent of patients in arm A suffered $\geq$ grade 2 late GI toxicity as compared to $9.4 \%$ in arm B. Concerning GU toxicities $2.7 \%$ of patients in arm A had $\geq$ grade 2 late adverse events while on arm B $4.2 \%$ corresponding rates were reported (Table 2).

\section{Local DFS}

Five-year local DFS depending upon the respective stages observed in our study for arms A and B were: (I) stage 1b2, $80 \%$ and $71 \%$ [hazard ratio (HR) $1.11 ; 95 \%$ confidence Interval (CI): $0.34-3.65, \mathrm{P}=0.86]$, respectively; (II) stage 2a, $80 \%$ and $83 \%$ (HR 0.92; 95\% CI: 0.37-2.29, $\mathrm{P}=0.91$ ); (III) stage $2 \mathrm{~b}, 63 \%$ and $72 \%$ (HR 0.81; 95\% CI: $0.63-1.04$, $\mathrm{P}=0.12$ ); (IV) stage $3 \mathrm{a}, 60 \%$ and $50 \%$ (HR 1.13; $95 \%$ CI: $0.42-2.9, \mathrm{P}=0.85$ ); (V) stage $3 \mathrm{~b}, 51 \%$ and $63 \%$ (HR 0.84; 95\% CI: $0.66-1.06, \mathrm{P}=0.15)$ and (VI) for stage $4 \mathrm{a}$, we have taken 3 -year results because none of the patient survived beyond 40 months in both the arms. So, in stage 4a 3-year DFS was $17 \%$ each in arm A and arm B. (HR 1.0; $95 \%$ CI: 0.22-4.6) (Figure 1). 
Table 2 Late adverse events

\begin{tabular}{lccc}
\hline Grade & Arm A & Arm B & P value \\
\hline Gastrointestinal & 20 & 18 & 0.26 \\
1 & 9 & 15 & 0.27 \\
2 & 4 & 5 & 0.84 \\
3 & 0 & 0 & - \\
4 & & & \\
Genitourinary & & 10 & 0.83 \\
1 & 9 & 7 & 0.72 \\
2 & 5 & 2 & 0.85 \\
3 & 2 & 0 & - \\
4 & 0 & & \\
\hline
\end{tabular}

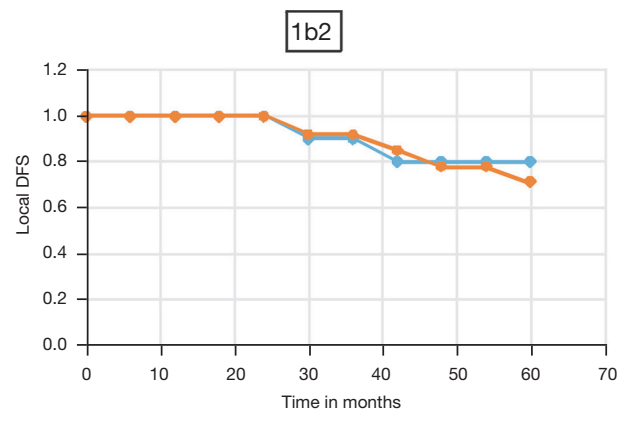

$2 b$

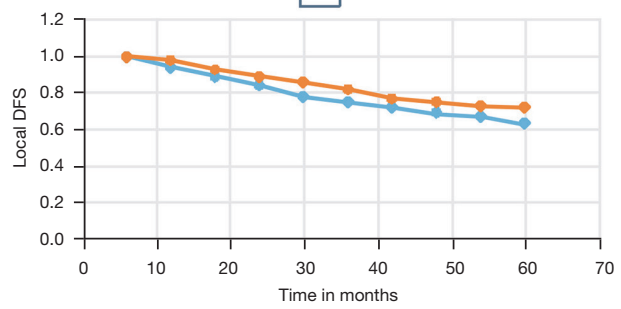

$3 b$

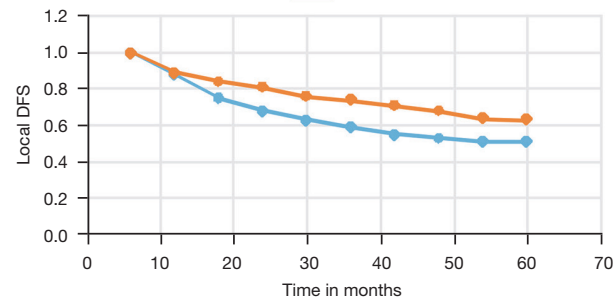

Figure 1 Stage wise 5-year local disease-free survival (DFS).

\section{OS}

Five-year OS were also not statistically different the two treatment regime arms. In stage $1 \mathrm{~b} 2$ we observed 5 -year OS of $80 \%$ in arm A and $85 \%$ in arm B (HR 0.84; $95 \%$ CI: $0.28-2.56, \mathrm{P}=0.79)$. In stage $2 \mathrm{a}$, it was $90 \%$ and $83 \%$, respectively (HR 1.28 ; $95 \%$ CI: $0.30-5.43, \mathrm{P}=0.75$ ). In stage $2 \mathrm{~b}$, reported OS was $71 \%$ and $76 \%$, respectively (HR 0.90 ; 95\% CI: $0.69-1.18, \mathrm{P}=0.47)$. In stage $3 \mathrm{a}$, it was $60 \%$ and $50 \%$, respectively (HR 1.13; 95\% CI: $0.42-2.90, \mathrm{P}=0.85$ ). In stage $3 \mathrm{~b}$, it was $56 \%$ and $63 \%$, respectively in arm $\mathrm{A}$ and arm B (HR 0.83; 95\% CI: 0.66-1.05, P=0.13). And in stage $4 \mathrm{a}$, as reported above none of the patients survived beyond 40 months (Figure 2).

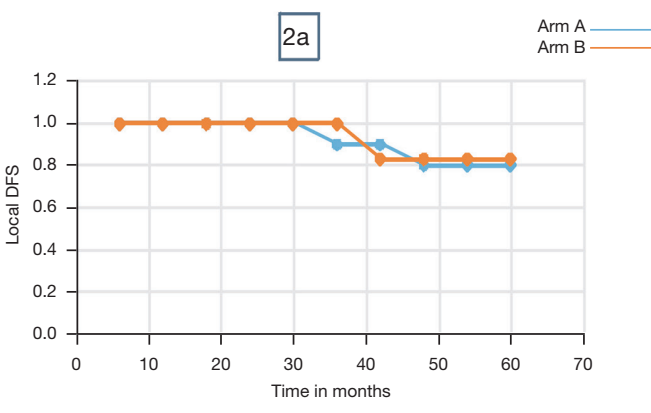

$3 a$

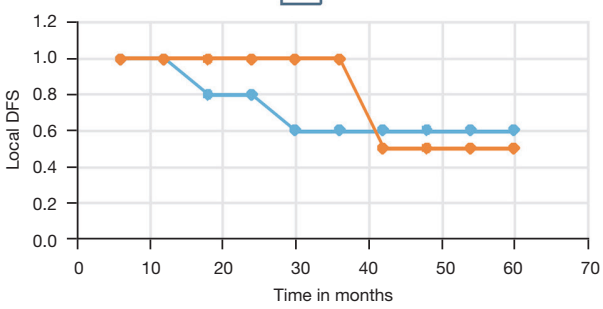

$4 a$

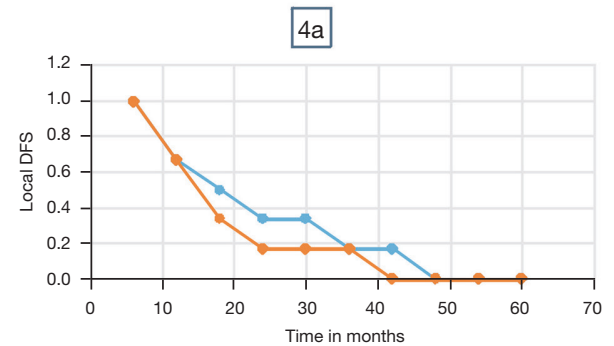




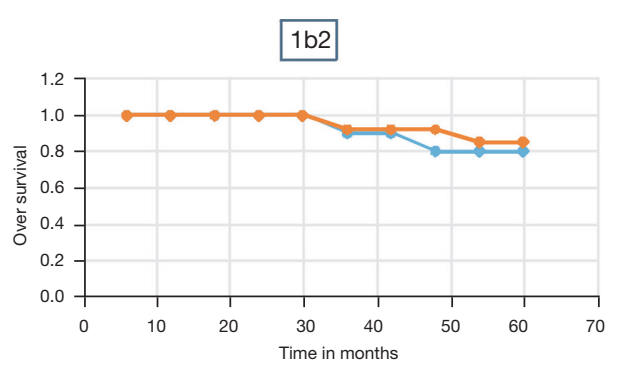

$2 b$

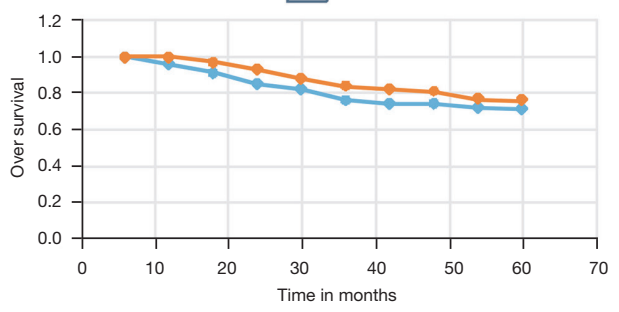

$3 b$

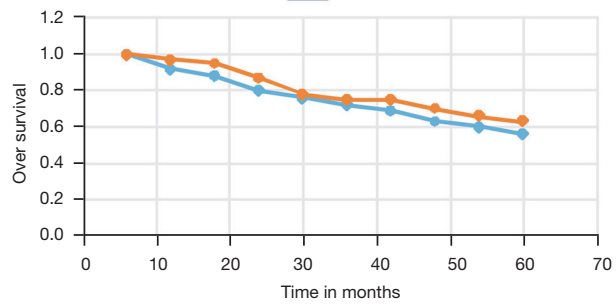

Figure 2 Stage wise 5-year overall survival (OS).

\section{Discussion}

American Brachytherapy Society (ABS) consensus guidelines for carcinoma cervix treated with HDR-BCT (13), reported that equivalent doses in 2 Gy fractions $\left(\mathrm{EQD}_{2}\right)$ in the range of $80-85 \mathrm{~Gy}$ at point $\mathrm{A}$ are acceptable for a range of fractionation schedules of HDR-BCT in combination with EBRT to maximize local control. Although larger the fraction size, the higher the risk of normal tissue toxicity. As for this study, while calculating the $\mathrm{EQD}_{2}$ we considered $\alpha / \beta$ value of $10 \mathrm{~Gy}$ for tumour tissues and $3 \mathrm{~Gy}$ for normal tissues. The $\mathrm{EQD}_{2}$ dose for tumour at point A was calculated as 79.8 Gy for arm A and 80 Gy for arm B. While for normal tissues $\mathrm{EQD}_{2}$ was $93.4 \mathrm{~Gy}$ for arm A and 96.8 Gy in arm B.

Orton et al. (14) in an analysis of data obtained from a survey of 56 institutions showed that the 5 -year survival was statistically significantly better for HDR treatments with the apparent geometrical advantage of HDR-BCT in reducing hot spots for rectal and bladder doses relative to

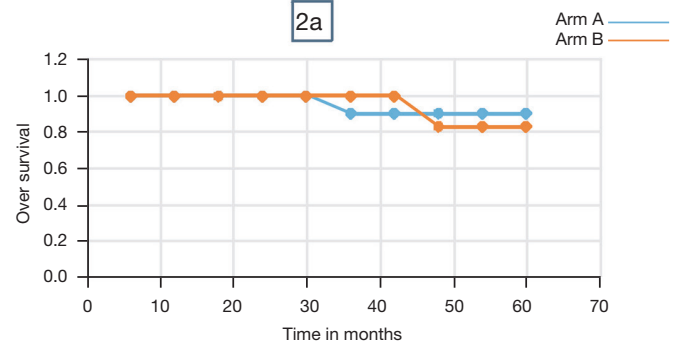

$3 a$

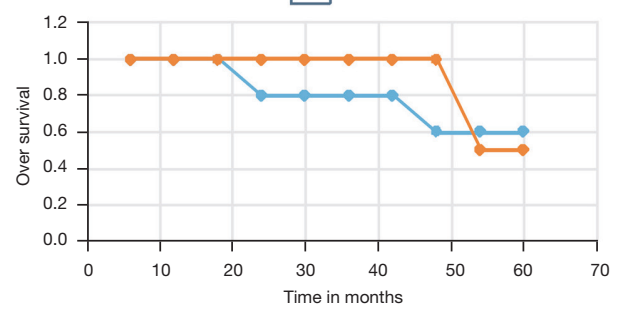

$4 a$

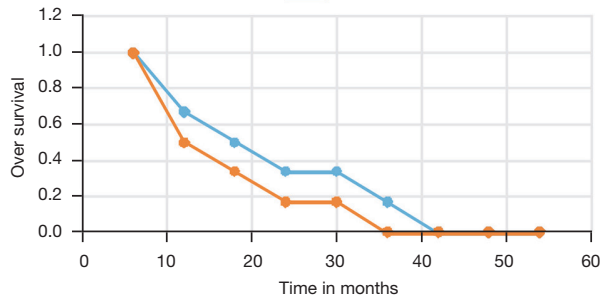

point A dose. They also reported that fractionation of HDR treatment significantly influenced toxicity with morbidity rates highly significantly lower for point A doses/fraction $\leq 7$ Gy compared to $>7$ Gy for both severe and moderate injuries with $\mathrm{P}<0.001$. ABS also recommended that the individual fraction size in HDR-BCT should be <7.5 Gy with a total of 4-8 applications. However, they also added that these recommendations were not adequately tested and were inferior to clinical experience (11).

The Indian Council of Medical Research (ICMR) Consensus document for the management of cancer cervix developed for Indian settings strongly recommends the use of HDR-BCT for cervical carcinoma, with 3-5 fractions of 6-7.5 Gy to point A each once weekly. The recommendations on other HDR fractionation schedules are still investigational as per the task force committee guidelines (15). Even the recently published Indian Brachytherapy Society Guidelines for radiotherapeutic management of cervical cancer (16), recommended limiting 
the dose per fraction to less than or equal to $7 \mathrm{~Gy}$ when using HDR-BCT for cervical tumours. However, they suggested that to respect the overall treatment time of less than or equal to 56 days, higher doses of up to 9 Gy can be used.

ABS in 2012 (17) recommended that the total duration of EBRT and BCT should be limited to less than 8 weeks, as prolonged treatment duration leads to a decrease in local control and survival of approximately $1 \%$ per day. However, when BCT is delivered in per week fractions after the completion of whole EBRT (i.e., after 5 weeks), the total treatment duration exceeds $>8$ weeks, especially for 4 or more fraction schedules. This can compromise the local control as well as survival. To balance the treatment time effect with control/survival an optimum schedule should be chosen, whereby the total treatment gets completed within 56 days.

Sood et al. (18) found out that 2 fractions of HDR-BCT with 9 Gy per fraction or even 9.4 Gy per fraction, were safe and effective in cervical carcinoma management. They also concluded that these regimens did not lead to increased bladder or rectal toxicity. Patel et al. (19) too concluded that the two applications of HDR-BCT with 9 Gy per fraction was safe and effective with good local tumour control, good survival rates and manageable toxicity.

For this present study, local disease included the local recurrence excluding the pelvic and para-aortic lymph nodes. We have utilized 2009 FIGO staged and treated patients for inclusion in the study treated up to June 2016, whereby para-aortic lymphadenopathy was described under metastatic disease, the final analysis was done in June 2021. Though as per 2018 FIGO, paraaortic lymphadenopathy has been described as a regional disease, for the present study it was excluded from the analysis.

In this present study majority of the patients were in stages $2 \mathrm{~b}$ and $3 \mathrm{~b}$ (88\%). Five-year loco-DFS was $63 \%$ versus $72 \%$ in arm A versus arm B in stage $2 \mathrm{~b}$ and $51 \%$ versus $63 \%$ in arm $A$ and arm B of stage $3 b$, respectively. Patel et al. (19) reported $81.29 \%$ DFS with their 9 Gy per fraction experimental arm in stage $2 \mathrm{~b}$ and $50.58 \%$ DFS in stage $3 \mathrm{~b}$ disease. However, these results were for a period of 3 years. Nakano et al. (20) reported 10 years of local pelvic tumour control rates of $82 \%$ for stage 2 and $75 \%$ for stage 3 disease. These included the entire stage 2 and stage 3 disease with no separate subgroup analysis when we know that extension to parametrium in itself is a bad prognosticator. Though the results were not statistically significant for the 5-year DFS in this study, we observed that 8 Gy arm provided slightly better results. This could be due to the earlier completion of the whole treatment with
8 Gy schedules i.e., within $61 \pm 6$ days as compared to $6.5 \mathrm{~Gy}$ arm where treatment was completed in $69 \pm 6$ days.

Even this $61 \pm 6$ days treatment time with 8 Gy schedule is longer than the recommended time frame of 56 days. Such prolongation can influence tumour control and survival. However, Hong et al. (21) through a National Cancer Database (NCDB) study, reported that among 7,355 carcinoma cervix patients, the data derived cut point for treatment duration was distributed around 64 days. Though, they concluded that shorter treatment duration was associated with longer OS. Ways to cut short this overall treatment time have been tested in the literature, with some using: (I) interdigitated BCT, i.e., concomitant with external beam RT schedule (22), however, it provided similar results when compared to conventional schedule; (II using a lesser number of fractions, e.g., 18 Gy in 2 fractions (9 Gy per fraction). Patel et al. (19) obtained better local control rates and DFS provided the application was favourable.

Five-year OS was also not statistically different between the two treatment regime arms. In stage $1 \mathrm{~b} 2$ we observed 5 -year OS of $80 \%$ in arm A and $85 \%$ in arm B $(\mathrm{P}=0.77)$. In stage $2 \mathrm{a}-90 \%$ and $83 \%$ respectively $(\mathrm{P}=0.69)$. Stage $2 \mathrm{~b}$, reported $\mathrm{OS}$ was $71 \%$ and $76 \%$ respectively $(\mathrm{P}=0.47)$. In stage $3 \mathrm{a}$ it was $60 \%$ and $50 \%$ respectively $(\mathrm{P}=0.80)$. In stage $3 \mathrm{~b}$ it was $56 \%$ and $63 \%$ respectively in arm $\mathrm{A}$ and arm $\mathrm{B}(\mathrm{P}=0.13)$. The 5 -year OS rates as reported by Nakano et al. (20) trial were $69 \%$ for stage 2 and $56 \%$ for stage 3 . Again, no separate subgroup analysis was done in their trial. A recent trial by Balasubramaniam et al. (23) reported 5-year survival rates of $85 \%$ for stage 2 and $71.1 \%$ for stage 3 patients treated with standard radiation and chemotherapy arm.

Grade 2 and above toxicities were slightly higher in arm B but the results were not statistically significant. Thus, at a comparable toxicity level, 24 Gy in three fractions is an acceptable, convenient BCT regime in treating carcinoma cervix, reducing the overall treatment time. Based on this trial we have standardized our HDR-BCT dose at 8 Gy for 3 fractions with one fraction per week.

The non-randomized and retrospective nature must be considered as the possible shortcomings of this trial. Also, we were not able to report on other late complications as the data was not complete/missing from the case records. Moreover, quality of life issues at 5 years is also not reported.

\section{Conclusions}

To conclude we have reported the 5-year survival outcomes 
stage and sub-group-wise for cervical carcinoma patients treated at a tertiary care centre. Moreover, based on our results we suggest the use of 8 Gy per fraction HDR BCT dose in 3 applications for the treatment of cervical carcinoma.

\section{Acknowledgments}

Funding: None.

\section{Footnote}

Reporting Checklist: The authors have completed the STROBE reporting checklist. Available at https://tro. amegroups.com/article/view/10.21037/tro-21-19/rc

Conflicts of Interest: All authors have completed the ICMJE uniform disclosure form (available at https://tro.amegroups. com/article/view/10.21037/tro-21-19/coif). The authors have no conflicts of interest to declare.

Etbical Statement: The authors are accountable for all aspects of the work in ensuring that questions related to the accuracy or integrity of any part of the work are appropriately investigated and resolved. The study was conducted in accordance with the Declaration of Helsinki (as revised in 2013). The study was approved by the institutional ethics committee of Faculty of Medicine, JN Medical College, Aligarh Muslim University (No. IECJNMC/395) and individual consent for this retrospective analysis was waived.

Open Access Statement: This is an Open Access article distributed in accordance with the Creative Commons Attribution-NonCommercial-NoDerivs 4.0 International License (CC BY-NC-ND 4.0), which permits the noncommercial replication and distribution of the article with the strict proviso that no changes or edits are made and the original work is properly cited (including links to both the formal publication through the relevant DOI and the license). See: https://creativecommons.org/licenses/by-nc-nd/4.0/.

\section{References}

1. Stewart AJ, Viswanathan AN. Current controversies in high-dose-rate versus low-dose-rate brachytherapy for cervical cancer. Cancer 2006;107:908-15.

2. Patel FD, Sharma SC, Negi PS, et al. Low dose rate vs. high dose rate brachytherapy in the treatment of carcinoma of the uterine cervix: a clinical trial. Int J Radiat Oncol Biol Phys 1994;28:335-41.

3. Fu KK, Phillips TL. High-dose-rate versus low-dose-rate intracavitary brachytherapy for carcinoma of the cervix. Int J Radiat Oncol Biol Phys 1990;19:791-6.

4. Hareyama M, Sakata K, Oouchi A, et al. High-dose-rate versus low-dose-rate intracavitary therapy for carcinoma of the uterine cervix: a randomized trial. Cancer 2002;94:117-24.

5. Inoue T. The trail of the development of high-dose-rate brachytherapy for cervical cancer in Japan. Jpn J Clin Oncol 2003;33:327-30.

6. Teshima T, Inoue T, Ikeda H, et al. High-dose rate and low-dose rate intracavitary therapy for carcinoma of the uterine cervix. Final results of Osaka University Hospital. Cancer 1993;72:2409-14.

7. Wang X, Liu R, Ma B, et al. High dose rate versus low dose rate intracavity brachytherapy for locally advanced uterine cervix cancer. Cochrane Database Syst Rev 2010;(7):CD007563.

8. Petereit DG, Sarkaria JN, Potter DM, et al. High-doserate versus low-dose-rate brachytherapy in the treatment of cervical cancer: analysis of tumor recurrence--the University of Wisconsin experience. Int J Radiat Oncol Biol Phys 1999;45:1267-74.

9. Lertsanguansinchai P, Lertbutsayanukul C, Shotelersuk $\mathrm{K}$, et al. Phase III randomized trial comparing LDR and HDR brachytherapy in treatment of cervical carcinoma. Int J Radiat Oncol Biol Phys 2004;59:1424-31.

10. Viswanathan AN, Creutzberg CL, Craighead P, et al. International brachytherapy practice patterns: a survey of the Gynecologic Cancer Intergroup (GCIG). Int J Radiat Oncol Biol Phys 2012;82:250-5.

11. Nag S, Erickson B, Thomadsen B, et al. The American Brachytherapy Society recommendations for high-doserate brachytherapy for carcinoma of the cervix. Int J Radiat Oncol Biol Phys 2000;48:201-11.

12. Petereit DG, Pearcey R. Literature analysis of high dose rate brachytherapy fractionation schedules in the treatment of cervical cancer: is there an optimal fractionation schedule? Int J Radiat Oncol Biol Phys 1999;43:359-66.

13. Viswanathan AN, Beriwal S, De Los Santos JF, et al. American Brachytherapy Society consensus guidelines for locally advanced carcinoma of the cervix. Part II: highdose-rate brachytherapy. Brachytherapy 2012;11:47-52 .

14. Orton CG, Seyedsadr M, Somnay A. Comparison of high and low dose rate remote afterloading for cervix cancer 
and the importance of fractionation. Int J Radiat Oncol Biol Phys 1991;21:1425-34.

15. Consensus Document for the Management of Cancer Cervix. Indian Council of Medical Research, 2016. Available online: https://main.icmr.nic.in/sites/default/ files/reports/Cervix\%20Cancer.pdf

16. Mahantshetty U, Gudi S, Singh R, et al. Indian Brachytherapy Society Guidelines for radiotherapeutic management of cervical cancer with special emphasis on high-dose-rate brachytherapy. J Contemp Brachytherapy 2019;11:293-306.

17. Viswanathan AN, Thomadsen B; American Brachytherapy Society Cervical Cancer Recommendations Committee, et al. American Brachytherapy Society consensus guidelines for locally advanced carcinoma of the cervix. Part I: general principles. Brachytherapy 2012;11:33-46.

18. Sood BM, Gorla G, Gupta S, et al. Two fractions of highdose-rate brachytherapy in the management of cervix cancer: clinical experience with and without chemotherapy. Int J Radiat Oncol Biol Phys 2002;53:702-6.

doi: $10.21037 /$ tro-21-19

Cite this article as: Khan M, Hussain MAB, Siddiqui SA, Akram M. Five-year survival outcomes with two different high dose rate brachytherapy schedules used in the treatment of cervical carcinoma. Ther Radiol Oncol 2022;6:2.
19. Patel FD, Kumar P, Karunanidhi G, et al. Optimization of high-dose-rate intracavitary brachytherapy schedule in the treatment of carcinoma of the cervix. Brachytherapy 2011;10:147-53.

20. Nakano T, Kato S, Ohno T, et al. Long-term results of high-dose rate intracavitary brachytherapy for squamous cell carcinoma of the uterine cervix. Cancer 2005;103:92-101.

21. Hong JC, Foote J, Broadwater G, et al. Data-Derived Treatment Duration Goal for Cervical Cancer: Should 8 Weeks Remain the Target in the Era of Concurrent Chemoradiation? JCO Clin Cancer Inform 2017;1:1-15.

22. Patidar AK, Kumar HS, Walke RV, et al. Evaluation of the response of concurrent high dose rate intracavitary brachytherapy with external beam radiotherapy in management of early stage carcinoma cervix. J Obstet Gynaecol India 2012;62:562-5.

23. Balasubramaniam G, Gaidhani RH, Khan A et al. Survival rate of cervical cancer from a study conducted in India. Indian J Med Sci 2021;73:203-11. 